\title{
CORRIGENDUM
}

doi:10.1038/nature20585

\section{Corrigendum: The Asian monsoon over the past 640,000 years and ice age terminations}

Hai Cheng, R. Lawrence Edwards, Ashish Sinha, Christoph Spötl, Liang Yi, Shitao Chen, Megan Kelly, Gayatri Kathayat, Xianfeng Wang, Xianglei Li, Xinggong Kong, Yongjin Wang, Youfeng Ning \& Haiwei Zhang

Nature 534, 640-646 (2016); doi:10.1038/nature18591

In this Article, the basis for the spectral analysis in Fig. 4 was not clear. The analysis was based upon the past 400,000 years of record, not the full 640,000 years of record. Details in the Methods are correct, but elsewhere the basis is stipulated as the full 640,000 years. We analysed the shorter version of the record because the precision of the dates of the cave record is considerably worse over the period 400,000 to 640,000 years ago. Thus, the spectral analysis of the full record is less robust than for the past 400,000 years only. For completeness, in Fig. 1 of this Corrigendum, we show the original Fig. 4 (which covers the past 400,000 years) along with analogous graphs covering the past 640,000 years. We argue that the original analysis is more robust because of smaller dating uncertainties. Thus, our original conclusions stand.

We thank S. C. Clemens for bringing this issue to our attention. The original Article has not been corrected online.
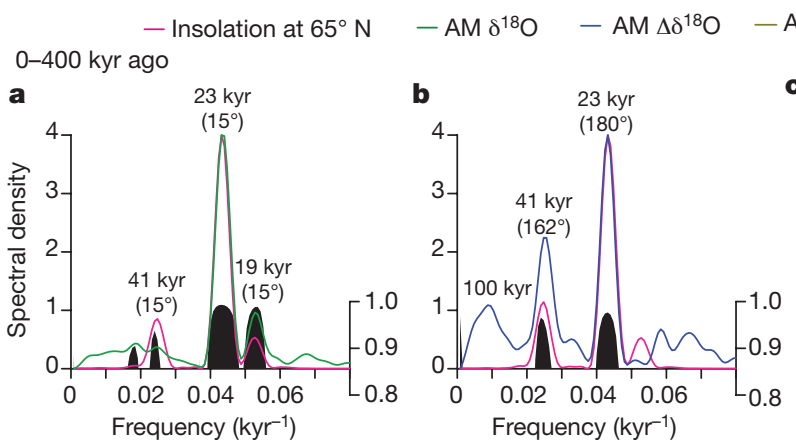

Antarctic $\Delta \delta \mathrm{D}$

- Coherency
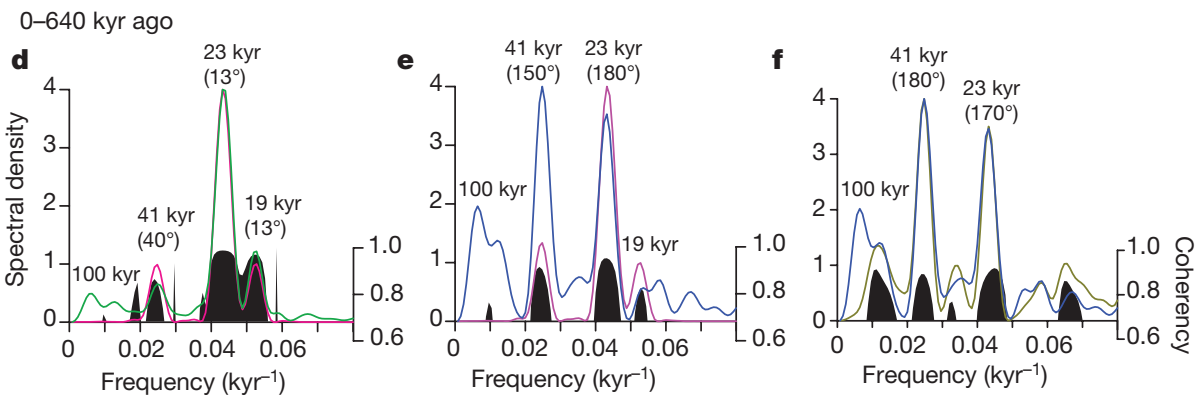

Figure 1 | Comparison of Fig. 4 of the original Article with analogous graphs covering the longer period of the past 640,000 years. a-c, The original Fig. 4 , an analysis of the past 400,000 years. d-f, An analysis of the past 640,000 years. Compared are insolation, the Asian monsoon (AM), the residual AM and detrended Antarctic $\delta \mathrm{D}$ records. See the legend of the original Fig. 4 for descriptions of the panels, in which those of panels a-c can also be read as those for panels $\mathbf{d}-\mathbf{f}$. 